\title{
SOME PHARMACOLOGICAL PROPERTIES OF ALTHESIN (CT1341) IN MAN
}

\author{
Charles E. Hope, T.W. Wilson, and Gordon M. Wyant ${ }^{\circ}$
}

The Development of Althesin (CT1341), a relatively new intravenous steroid anaesthetic complex, has led to renewed interest in the potential of steroid anaesthesia in man. It was the report of Hans Selye in $1941^{1}$ which described the hypnotic properties of steroids that led to the research which resulted in the ultimate development of hydroxydione. During that time it became apparent that steroid anaesthetics had the advantages, firstly, of a greater therapeutic ratio and thus a greater margin of safety than their barbiturate counterparts and, secondly, of progressive elimintion from the blood by the liver, thus overcoming the need for redistribution in order to hasten recovery from anaesthesia. While hydroxydione possessed these advantages it was found less than ideal for clinical use as it produced pain on injection, a high incidence of post-anaesthetic thrombophlebitis, delayed onset of anaesthesia and an unacceptably long duration of action. The suggestion by Robertson and Wynn-Williams ${ }^{2}$ that certain of the metabolites of hydroxydione might be responsible for much of its anaesthetic activity led to further research into steroid anaesthesia. As a result, Glaxo compound GR2/146 was developed. Although this compound was unsuitable in clinical practice because of its side effects, the knowledge which was acquired with regard to the relationship between the chemical structure and the anaesthetic activity of steroids proved invaluable. Subsequently compound GR2/234 (alphaxalone) was developed. This compound has a rapid onset of action and high potency, together with a wide safety margin. Alphaxalone shares with other steroids the property of poor solubility and this was only in part overcome by the use of Cremophor EL (polyoxyethylated castor oil) as solvent for the substance. However, it was found that the addition of a small amount of related steroid GR2/1574 (alphadolone acetate) increased the solubility of alphaxalone in Cremophor EL more than threefold. This latter compound also has anaesthetic properties similar to and additive to those of alphaxalone.

Althesin is a mixture of these two steroids and is available in ampoules containing the following formulation:

Alphaxalone (3-hydroxy-5-pregnane-11.20 dione) $9 \mathrm{mg} / \mathrm{ml}$

Alphadalone acetate (21-acetoxy-3-hydoxy-5-pregnane-11.20 dione) $3 \mathrm{mg} / \mathrm{ml}$

Cremophor EL (B.A.S.F.) $200 \mathrm{mg} / \mathrm{ml}$

Sodium Chloride AR $2.5 \mathrm{mg} / \mathrm{ml}$

Water for injection B.P. to 100 per cent

'From the Departments of Anaesthesia and Pharmacology, University of Saskatchewan.

The Study was undertaken within the framework of a Development Grant by the Canadian Foundation for the Advancement of Clinical Pharmacology.

Supplies of Althesin have been made available by Messrs. Glaxo Canada Limited, Toronto.

$$
572
$$

Canad. Anaesth. Soc. J., vol. 22, no. 5, September 1975 
TABLE I

Balanced Incomplete Block Design

\begin{tabular}{ccc}
\hline Subject & First injection & Second injection \\
\hline 1 & $\mathrm{C}$ & $\mathrm{A}$ \\
2 & $\mathrm{~B}$ & $\mathrm{~A}$ \\
3 & $\mathrm{~A}$ & $\mathrm{~B}$ \\
4 & $\mathrm{C}$ & $\mathrm{B}$ \\
5 & $\mathrm{~A}$ & $\mathrm{C}$ \\
6 & $\mathrm{~B}$ & $\mathrm{C}$ \\
\hline $\mathrm{A}=40, \mathrm{~B}=60, \mathrm{C}=80$ microlitres Althe- \\
$\sin / \mathrm{Kg}$ body weight.
\end{tabular}

The prepared solution is slightly viscid with a $\mathrm{pH}$ of about 7.0 and is isotonic with blood. In practical use the dosage of Althesin, as with all mixtures, is expressed in terms of volume rather than weight of actual active drug.

\section{Materials ANd Methods}

\section{Subjects}

The subjects used in the studies were eight male students, aged between 20 and 29 years (mean 23.4; S.D. 2.72), who were in good health with no past history of any significant illness and who were not apparently taking any drugs or medications. After preliminary consent had been obtained, the subjects were submitted to a complete physical examination by a physician not involved in the study. In addition, the standard 12-lead ECG was recorded and examined by a cardiologist. The subjects who were finally accepted for the investigation then had the details of the experiment explained to them before their final consent was obtained. They were asked to report on the morning of the study completely rested and totally fasting. Of the eight subjects used, six were included in a balanced incomplete block design (BIBD) study, each subject receiving two of the three chosen dose levels. The doses finally arrived at were 40,60 , and $80 \mu \mathrm{l} / \mathrm{Kg}$ body weight, 120 and $160 \mu \mathrm{l} / \mathrm{Kg}$ having been discarded during pilot runs on the other two subjects for reasons to be reported later. The block design is illustrated in Table I.

\section{Design}

In order to obtain a pure response to Althesin, none of the subjects received any premedication. The various transducers were applied with the subjects lying on a Tilt Table. During this time they were familiarized with the environment and with the equipment and were introduced to all members of the research team. Baseline recordings were then made over a period of 15 minutes. At this point also a baseline assessment of fine motor function was obtained. In addition, their response to the Valsalva manoeuvre and to passive tilting to 50 degrees from the horizontal was measured. Thereafter, further baseline measurements were made for another 15-minute period. Anaesthesia was then induced with Althesin. The precalculated volume was injected at a constant rate of $1 \mathrm{ml} / 10 \mathrm{sec}$ into the tubing of the intravenous infusion line close to the hand, and was flushed through with a quantity of normal saline, again at a rate of $1 \mathrm{ml} / 10 \mathrm{sec}$. During the induc- 
TABLE II

Questionnatre Given to the Subjects after Recovery

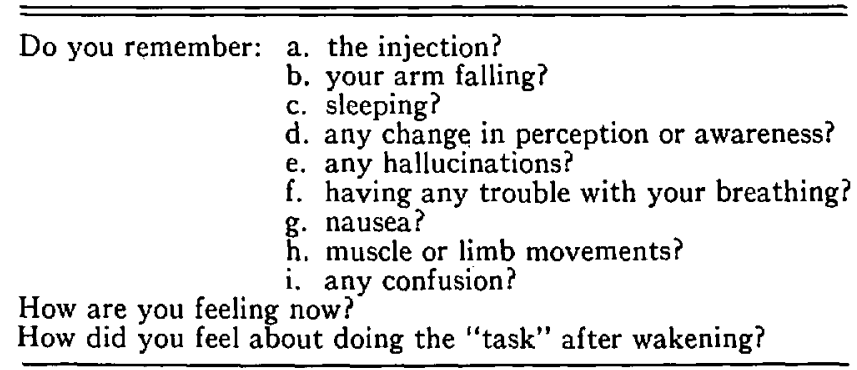

tion phase, the anaesthetic phase and the recovery phase various observations and responses were identified and noted. After the subjects had exhibited clinical recovery, repeated assessments were made of their fine motor function until that too had returned to normal. Valsalva manoeuvres and passive tilts were then repeated. Finally, the subject was asked to answer the questionnaire reproduced in Table II.

After a rest period of one hour, during which time the subjects were allowed to assume any position comfortable to them, the study was repeated with the second quantity according to the block design. None of the observers were aware of the coding of the BIBD until the end of the series.

After the second recovery phase was complete the subjects were allowed to rest in the Recovery room until they felt ready to go home. All subjects were sent home accompanied by a responsible adult.

\section{Measurements And Observations}

\section{Physiological Measurements}

The studies were carried out in an operating room with controlled environmental temperature and humidity. For the duration of the investigation the mean environmental temperature was $21.7^{\circ} \mathrm{C}$. On no occasion did the temperature vary by more than $\pm 1^{\circ} \mathrm{C}$. during any single experimental observation. The subjects lay on an OB Tilt Table (Olle Blomqvist, Rehab-Produkter AB, Stockholm). Full anaesthesia and resuscitation equipment were available.

The following variables were charted continuously using a Mingograf 81 chart recorder. The electrocardiogram was obtained using chest electrodes. Tidal volume and minute volume were measured with a Wright Electronic Respiration Monitor (B.O.C., Ltd.). The Wright transducer was mounted in a standard anaesthetic face mask which was held in position on the subject's face by the anaesthetists responsible for airway management. End-tidal carbon dioxide was measured using a Godard Capnograph B.E., the sampling being accomplished with a needle inserted through the anaesthetic face mask. Skin blood flow was assessed by digital photoplethysmography. The radial artery was cannulated percutaneously through a wheal of local analgesic using an $18 \mathrm{Ga}$. teflon catheter (C.R. Bardic, New Jersey, U.S.A.). Arterial cannulation was performed in the non-dominant limb and only in the presence of a competent ulnar artery. By this means a 
dynamic blood pressure waveform record was obtained and blood was easily available for gas analysis. Environmental and skin temperatures were recorded intermittently using an electric thermometer (Elektrolabratoriet,, Copenhagen). An intravenous infusion of 5 per cent Dextrose in water was set up in a dorsal hand vein in the non-dominant arm. This infusion line was used to administer the anaesthetic.

A task was given to the subject to assess fine motor function. The equipment used was a small block of wood, rather similar to a cribbage board, in which two parallel rows of holes had been drilled. The top row of 20 holes was filled with small wooden pegs. The bottom row of 20 holes was left empty. ${ }^{3}$ The task was to transfer the wooden pegs from the top row to the bottom row of holes as rapidly as possible over a period of 15 seconds. This was repeated at intervals of one minute until the same number of pegs had been transferred on three successive occasions. The number of pegs moved served as baseline for fine motor function.

The test was conducted on all occasions with the subjects supine. Before starting they were allowed to position the board until they were satisfied that they had it at an optimal position. A simple count-down procedure was used over a period of 5 seconds.

\section{Observations}

Onset of sleep - Immediately before the drug was injected, the subject was asked to raise his free arm to about $90^{\circ}$ from the horizontal and to move his fingers in a gentle rippling pattern. Sleep was considered to be complete when the arm fell down to the side.

Apnoea - Apnoea was gauged jointly by the anaesthetist responsible for airway management using clinical criteria and by an examination of the continuously charted respiratory variables. The duration of any apnoeic phase was similarly determined.

Necessity for artificial ventilation or oxygen supplementation was determined on clinical grounds by the anaesthetist responsible for airway management. Subject safety was a prime consideration at all times.

Involuntary muscle movements - Three independent observers contributed to the observation and recording of the presence of fine or gross involuntary muscle movements if they occurred.

Hiccough, cough and excessive salivation - These were reported by the anaesthetist responsible for airway management.

\section{Responses}

Awakening - After the immediate induction phase had been completed, the subject was given the command "Open your eyes!" at one-minute intervals. An identification of any response to this command (e.g. alteration in the recorded variables, movement of eyeballs, etc.) caused this command frequency to be increased to $2 /$ minute, and then $4 /$ minute. The subject was considered to be awake when he opened his eyes on command on more than 50 per cent of occasions.

Orientation as to time and place - The subject was considered orientated as to time and place when he was able to answer accurately the following questions: 


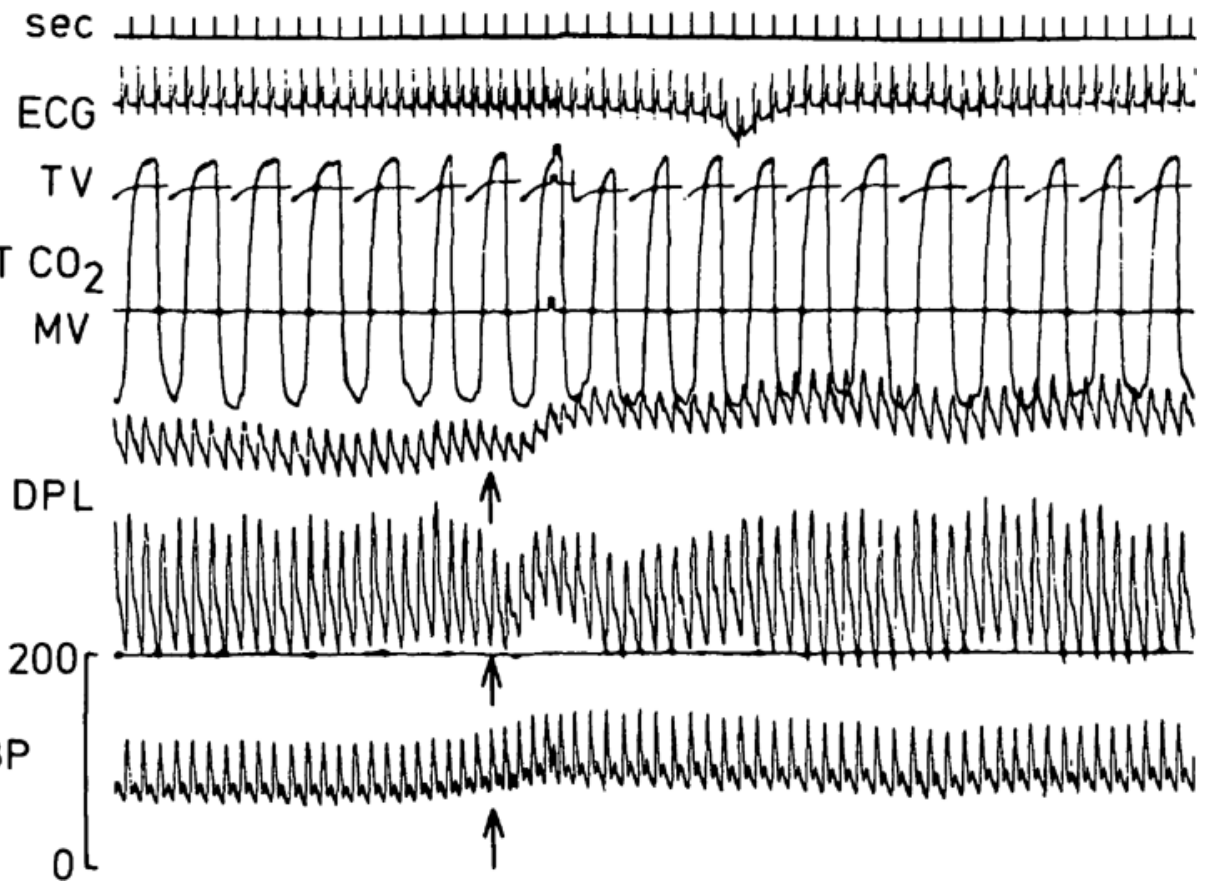

FiguRE 1. Peripheral vascular evoked responses and other parameters.

E-T: End-Tidal DPL: Digital Plethmysography

I. "Tell me your name?"

II. "Where are you?"

III. "What is the date today?"

Clinical recovery - After the above responses had been elicited the subject was asked to sit up on the table. When he was able to sit upright unaided he was considered to have recovered by clinical criteria.

Fine motor function - This was assessed as soon as clinical recovery was judged to be complete in the manner previously described.

Peripheral vascular responses - These were monitored during the control, anaesthesia and recovery phases. Both the spontaneous and evoked peripheral vascular responses observed during the control period were obtunded with the onset of anaesthesia. The peripheral vascular evoked response to the auditory command "open your eyes" was considered to be one of the first signs of lightening anaesthesia and was included as a criteron for increasing the frequency of this command in an attempt to obtain a more definitive endpoint to anaesthesia. It was hoped that in that way a more accurate dose response curve might be obtained.

Figure 1 illustrates a peripheral vascular evoked response together with all other parameters monitored.

\section{Subject Questionnaire}

The questionnaire was used in this study in an attempt to obtain subjective information about the response to Althesin. 


\section{Statistical Techniques}

To overcome the difficulty of identifying significant change following a specific pharmacological stimulus, the statistical monitoring techniques initially described by Lewis ${ }^{4}$ and more recently by Hope, Lewis, Perry and Gamble ${ }^{5}$ were used. Both the CUSUM method and Trigg's monitoring method were used. With these methods naturally occurring homeostatic fluctuations in physiological variables can be effectively smoothed out, thus removing the confusion that may result when attempting to identify the trend of a variable where many absolute values obtained at short intervals in time are available. In this study, the initial five measurements in each variable were used to obtain a standard "normal" control value for each subject, which was used to initiate the monitoring functions. The CUSUM technique allows detection of changes in the average of a series of values, determines at which time period the onset of such changes occurs and allows the estimation of a new average value following such changes. Trigg's monitoring method, while slightly more complicated to operate in practice than the CUSUM method, has the advantage that the level of confidence at which significant changes are indicated is more easily interpreted. The confidence levels determined by this method were used to establish whether or not there were significant increases or decreases in the level of the variable measures obtained in this study. A coordinate plot of the CUSUM and Trigg's tracking function interpretation is illustrated in Figure 2.

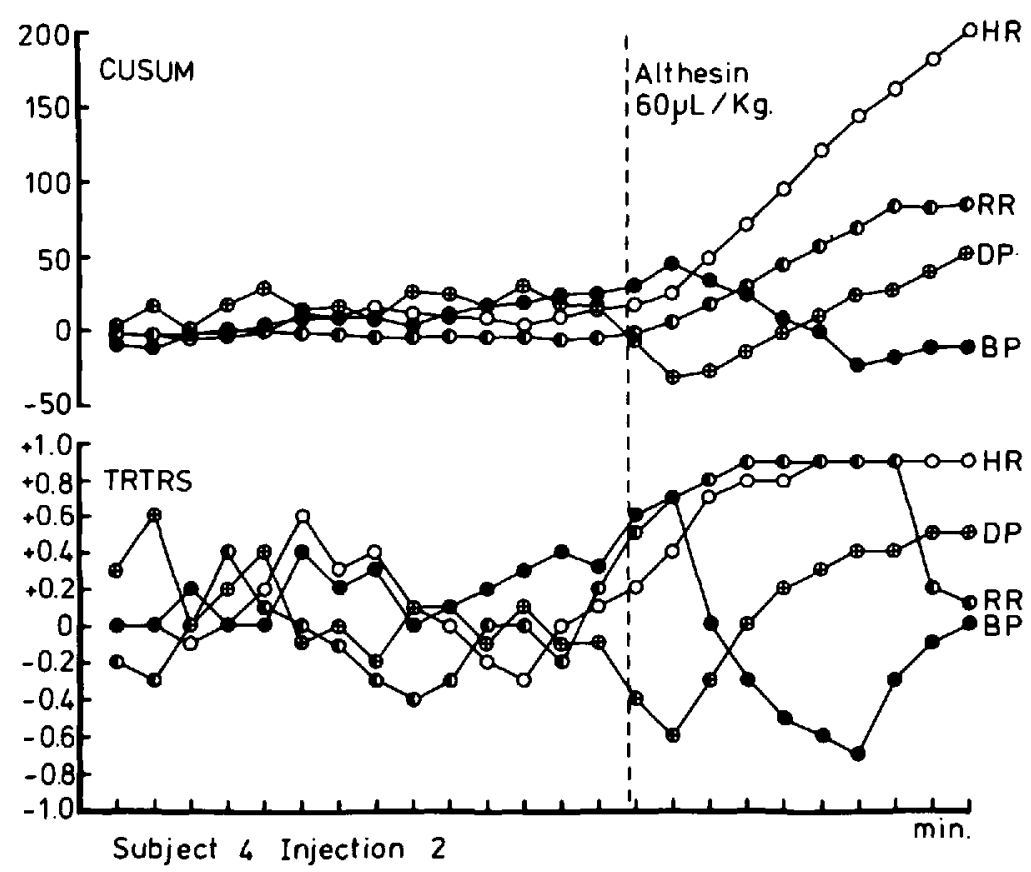

FIgURE 2, Coordinate plot of CUSUM and Trigg's Tracking Signal (TRTRS). 
TABLE III

Physiological Measurements

\begin{tabular}{ccccc}
\hline \hline Dose & HR(\%) & RR(\%) & \multicolumn{2}{c}{ BP(\%) } \\
\hline $40 \mu \mathrm{l} / \mathrm{Kg}$ & 90 & 90 & 70 & 80 \\
$60 \mu \mathrm{l} / \mathrm{Kg}$ & 98 & 95 & 70 & 90 \\
$80 \mu \mathrm{l} / \mathrm{Kg}$ & 98 & 98 & 70 & 90 \\
\hline
\end{tabular}

\section{Results}

\section{Physiological Measurements}

A representation of the chart recording obtained is shown in Figure 1. All responses were studied in relation to the control period of observation. Data were abstracted from the recordings at one-minute intervals at least.

1. ECG - no dysrhythmia was observed.

2. Cardiac ventricular rate was determined from the ECG recording and increased in all cases. The confidence level for each subject is given in Table III. It should be noted that these confidence levels apply at each dose level to particular subjects only and not to the entire group.

3. Respiratory Rate (Table III). The respiratory rate for each individual in terms of confidence levels also showed statistically significant increases directly related to increasing doses. This tendency, while noteworthy, is not significant statistically.

4. Blood pressure (Table III). There was a tendency for the blood pressure to increase transiently before falling. The remarks about heart rate and respiratory rate concerning applicability to individuals pertain in this case also.

The foregoing conclusions are confirmed by the statistical techniques previously described.

\section{Observations}

Onset of sleep - The end-point marking onset of sleep was that point in time at which the subject's arm fell from the $90^{\circ}$ elevation down to his side. At each dose level, this occurred at a mean time of 1.45 minutes from the beginning of the injection (Table IV).

Apnoea - In the six subjects included in the BIBD study, apnoea occurred only in one. In this individual, apnoea developed 10 seconds after the onset of sleep following the administration of $40 \mu \mathrm{l} / \mathrm{Kg}$; it lasted for 50 seconds. Following 80 $\mu \mathrm{l} / \mathrm{Kg}$ in the same subject, apnoea developed 5 seconds after the onset of sleep and lasted for a total of 55 seconds. His end-tidal $\mathrm{CO}_{2}$ level was 4.3 per cent and 4.4 per cent respectively at the time of administration of the two doses.

Apnoea did not occur at any dose level in the remaining five subjects. In this group, the end-tidal $\mathrm{CO}_{2}$ level was $5.77 \pm 0.37$ per cent over a range of 5.35 to 6.3 per cent.

Artificial ventilation or oxygen supplementation - Assisted ventilation was not required in any of the six subjects included in the BIBD series. In one individual who did not develop apnoea, but who had a period of marked hypoventilation, 


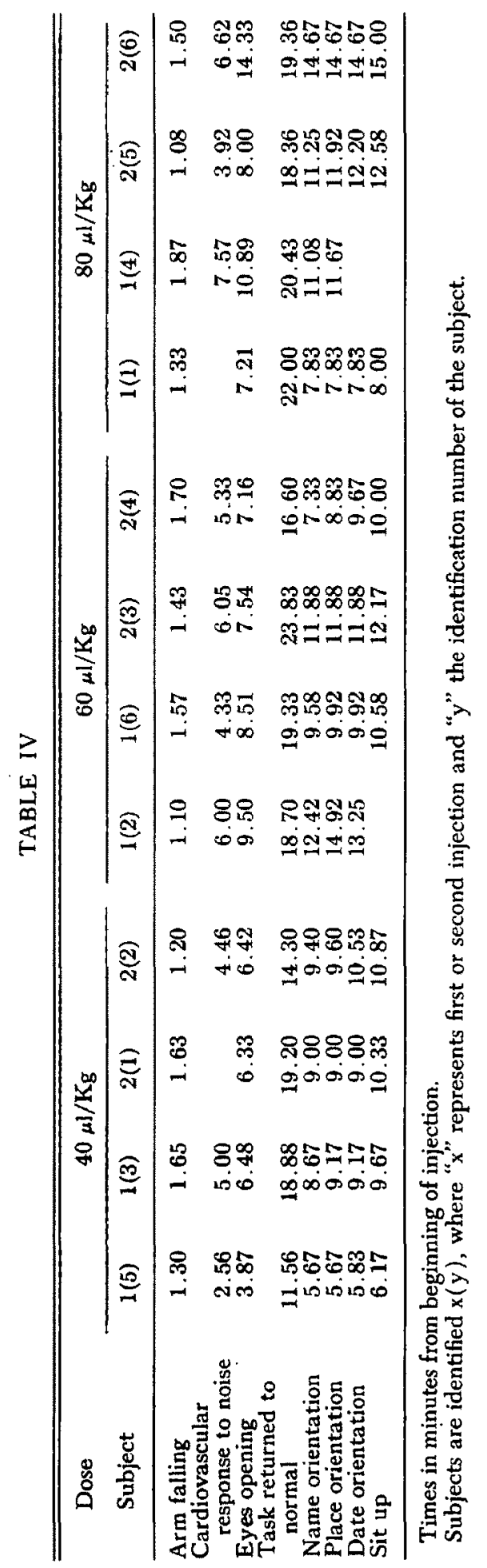




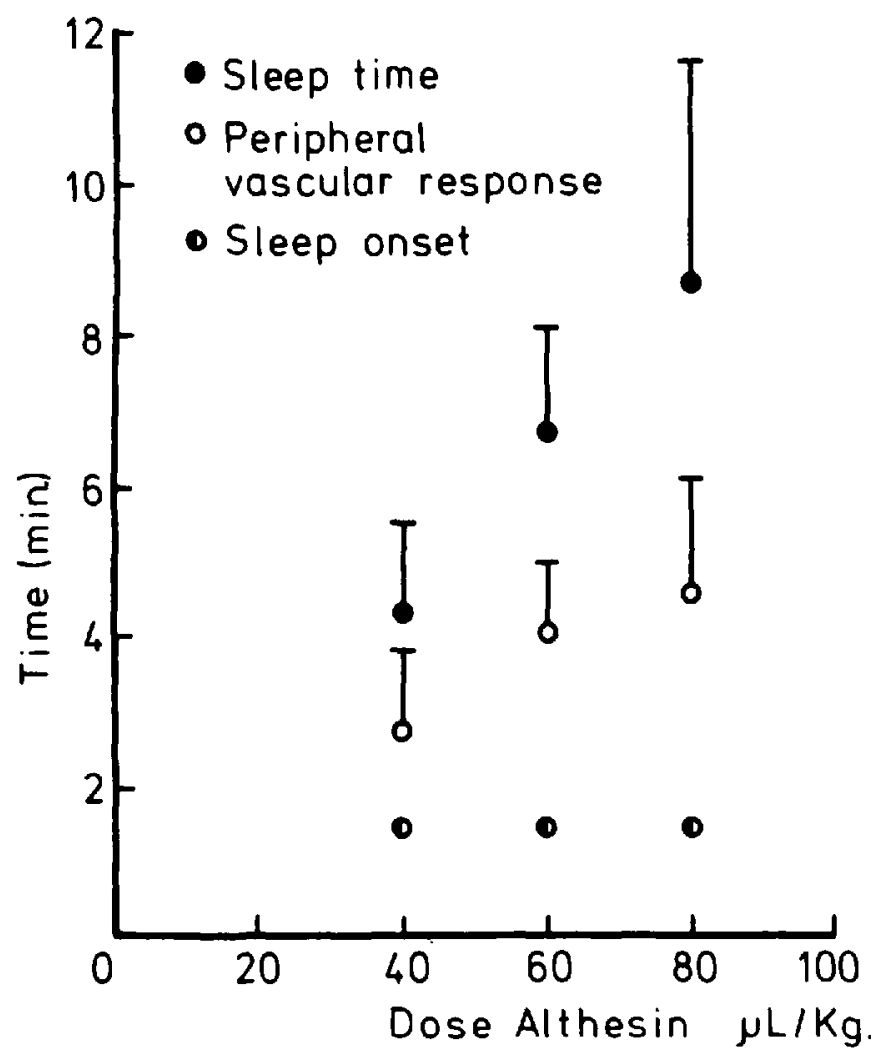

Figure 3. Onset of sleep, sleep time and peripheral vascular response in relation to dose.

oxygen supplementation of the inspired air was considered to be necessary on clinical grounds.

Involuntary muscle movements - Involuntary muscle movements occurred in 5 of the 12 observations in the BIBD series. At the $40 \mu \mathrm{l} / \mathrm{Kg}$-dose level slight twitching of the eyelids occurred in one subject. At the $60 \mu \mathrm{l} / \mathrm{Kg}$-dose level fine twitching over the left clavicle and gross movement of the left leg were observed in one other subject; hiccough and coughing occurred in yet another individual. At the $80 \mu \mathrm{l} / \mathrm{Kg}$-dose level more significant involuntary movements were seen. In one subject both muscle twitching and gross movement were observed in the right arm. In another twitching and fine clonus-type activity was seen in the right hand, biceps and shoulder girdle.

In addition to the involuntary movements, limb movements were seen in response to auditory stimuli on four occasions. These occurred very shortly before the subjects responded to the command to open their eyes. Accordingly it is considered that these were evoked responses.

Hiccough or Cough. Hiccough or cough was seen on one occasion only at the $60 \mu \mathrm{l} / \mathrm{Kg}$ level in the subject who was considered as a result to require oxygen supplementation.

Salivation - Extensive salivation was seen in one subject at the $60 \mu \mathrm{l} / \mathrm{Kg}$-dose 
level. This again was the one who developed coughing and hiccough and required the administration of oxygen.

\section{Responses}

Subject responses which were recorded included the peripheral vascular auditory evoked response, the time at which the subject awakened, was oriented as to place and time, and was able to sit up unaided. Completion of these responses was taken to indicate clinical recovery from Althesin anaesthesia. In addition, an assessment of fine motor function was made following clinical recovery. The times from the beginning of injection to the various endpoints are given in Table IV. The dose response graphs are illustrated in Figures 3 and 4. Statistical examination using an analysis of variance ${ }^{5}$ and student's $\mathrm{T}$ test showed, in this small series, no significance to variation in subject, dose or order of dose. There was no evidence of a cumulative effect.

During the control and recovery phases, both Valsalva and passive tilt responses were obtained in each of the subjects. While the results of such physiological stresses are to form part of a larger study, it is interesting to note that neither Valsalva nor the passive tilt responses returned to normal control levels until some time after all other assessments indicated that complete recovery had taken

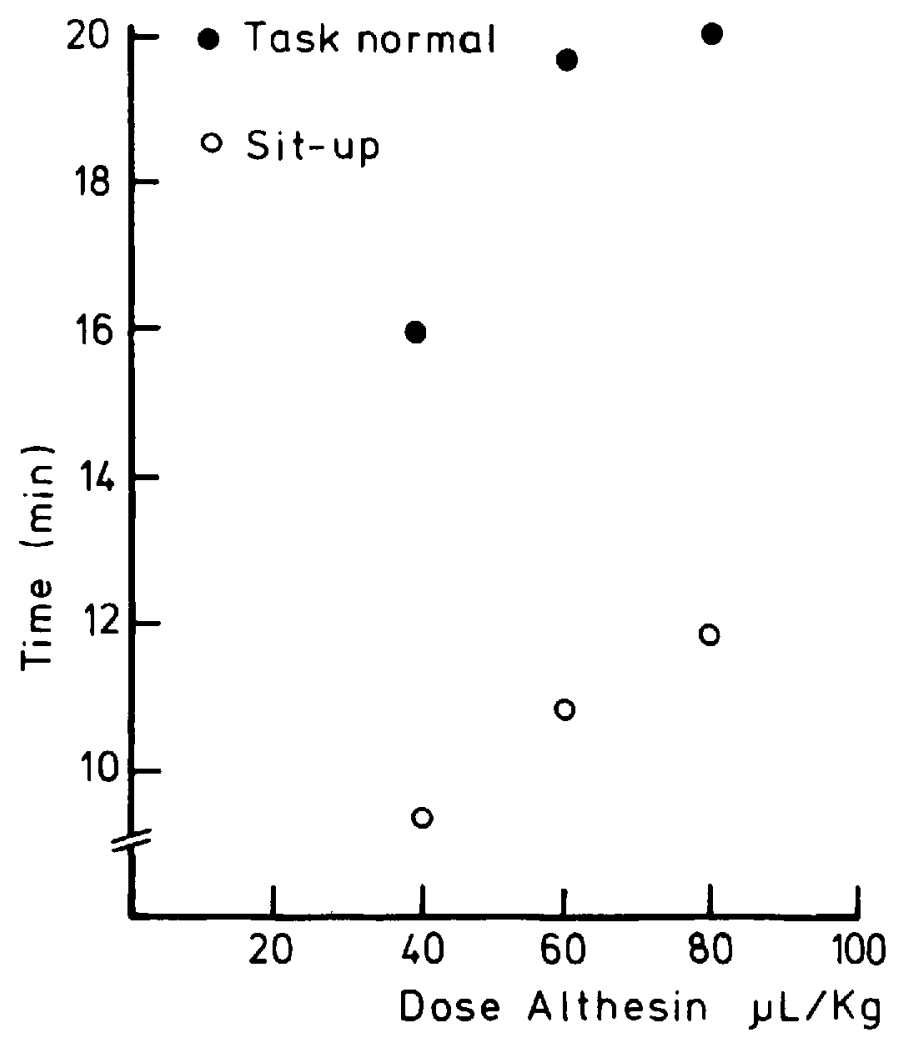

Figure 4. Return of normal functions in relation to dose of Althesin. 
TABLE V

Peripheral Vascular Responses

\begin{tabular}{rcccc}
\hline \hline & Control & Induction & Sleep & Reacting \\
\hline $40 \mu \mathrm{l} / \mathrm{Kg}$ & 1.19 & 1.07 & 2.55 & 1.69 \\
& 1.35 & 1.34 & 2.23 & 1.42 \\
Mean & 1.50 & 1.38 & 2.78 & 2.62 \\
$60 \mu \mathrm{l} / \mathrm{Kg}$ & 1.35 & 1.26 & 2.52 & 1.91 \\
& 1.07 & 1.00 & 1.57 & 1.33 \\
& 1.34 & 1.21 & 2.94 & 1.82 \\
Mean & 1.00 & 1.00 & 2.82 & 1.96 \\
$80 \mu \mathrm{l} / \mathrm{Kg}$ & 1.44 & 1.50 & 2.70 & 1.40 \\
& 1.21 & 1.18 & 2.51 & 1.63 \\
Mean & 1.00 & 1.00 & 1.88 & 1.26 \\
& 1.27 & 1.39 & 2.65 & 1.88 \\
& 1.34 & 1.25 & 4.13 & 2.41 \\
\hline
\end{tabular}

place. Further investigation is being carried out in this area, the details of which will be reported later.

\section{Peripheral Vascular Resistance}

The reaction of the peripheral vascular tree was calculated from the ratio of the height of the peripheral pulse wave to the dicrotic notch. Table $V$ gives the figures for the three-dose ranges with the exception of two tracings which were not sufficiently clear to allow calculations to be done. From this it will be seen that there was a small degree of vasoconstriction or no change at all at the time of induction. Whatever vasoconstriction was present was probably due to apprehension. With the onset of sleep quite marked vasodilation occurred in all subjects. This tended to regress as the individuals were reacting but had not yet returned to baseline values.

\section{Subject Questionnaire}

All subjects remembered the injection of the anaesthetic. None had trouble breathing and none were nauseated. One subject remembered his arm falling to his side in both dose ranges while none of the other five had any such recollection. The answer to the question "Do you remember sleeping?" was divided equally with the incidence decreasing as the dose increased. It may be noteworthy that three individuals did not remember with either of the two doses while the other three remembered with both doses. In reply to whether there was any change in perception or awareness, one volunteer stated that hearing was more acute with both the 40 and the $80 \mu \mathrm{l} / \mathrm{Kg}$-dose while one found this to be the case only with the larger dose and another only with the smaller dose. One stated that perception was more difficult on awakening after the $60 \mu \mathrm{l} / \mathrm{Kg}$. dose than after $40 \mu \mathrm{l} / \mathrm{Kg}$.

One individual admitted to dreams only with the $40 \mu \mathrm{l} / \mathrm{Kg}$ dose, while none of the others either dreamed or had hallucinations. One individual stated that he had one or two twitches in the right leg on awakening. One subject felt confused on awakening after the smaller dose but not after $80 \mu \mathrm{l} / \mathrm{Kg}$. Two felt slightly confused 
on awakening and one on falling asleep. Comments on the task revolved invariably around blurring vision for all volunteers but one, who said that the task was much clearer to him on awakening than during the control period. Three individuals commented that they had felt very relaxed after awakening from one of their two anaesthetics. One other individual felt sleepy.

No clear evidence emerges from these comments, except that from a subjective point of view this is an innocuous agent which in clinical doses causes few side effects.

\section{Pilot Study}

One individual was anaesthetized with a dose of $120 \mu \mathrm{l} / \mathrm{Kg}$ and one with 160 $\mu \mathrm{l} / \mathrm{Kg}$. The one who was given the smaller dose had massive muscle movements, prolonged hiccough and violent coughing; the one who received the higher of the two doses was similarly affected except that he did not have spasms of coughing. Both became somewhat cyanotic and oxygen administration was necessary. The entire episode lasted for a little less than five minutes and had completely resolved by the time the individuals awoke. There were no sequelae. Nevertheless, it was obvious that in unpremedicated man these are unacceptably high doses. Obviously, the phenomena which were observed are exaggerations of the minor muscle movements seen with all dose ranges of Althesin, being more frequent as doses increase (Table VI). Heart rate and blood pressure responses were not significant.

\section{Conclusions}

A number of interesting points arise from this study. In unpremedicated man at least, a dose of $80 \mu \mathrm{l} / \mathrm{Kg}$ should not be exceeded because of severe muscle movements, coughing, hiccough and similar phenomena. In the doses between 40 and $80 \mu \mathrm{l} / \mathrm{Kg}$, Althesin has no deleterious effects on heart rate, respiratory rate or blood pressure. Apnoea did not occur in this series except in one patient who had a lower than normal end-expiratory $\mathrm{CO}_{2}$ level, likely due to pre-anaesthetic hyperventilation. It is logical that under those circumstances the superimposition of an anaesthetic drug may evoke apnoea which would not occur at normal carbon dioxide levels.

The most fascinating finding is that demonstrated in Figure 4. From this it would appear that the onset of sleep, which is rather prolonged with Althesin at the injection rates used in this study, is not influenced by the total dose. The sleep time is in direct straight-line relationship to the injected dose. However, the auditory evoked response (the time at which vascular responses can be demonstrated following verbal stimulation) tends to lie on a curve indicating that with increasing doses the point in time at which these responses reappear is not correspondingly prolonged. To the best of our knowledge this has never been demonstrated for any intravenous anaesthetic agent. On the other hand, before definitive conclusions can be drawn it must be realized that with only four tests in each group and only a three-point reference this finding must be corroborated before final conclusions can be drawn. However, if it is confirmed, it would then appear that the hearing function is less depressed by this drug than the corresponding increase 


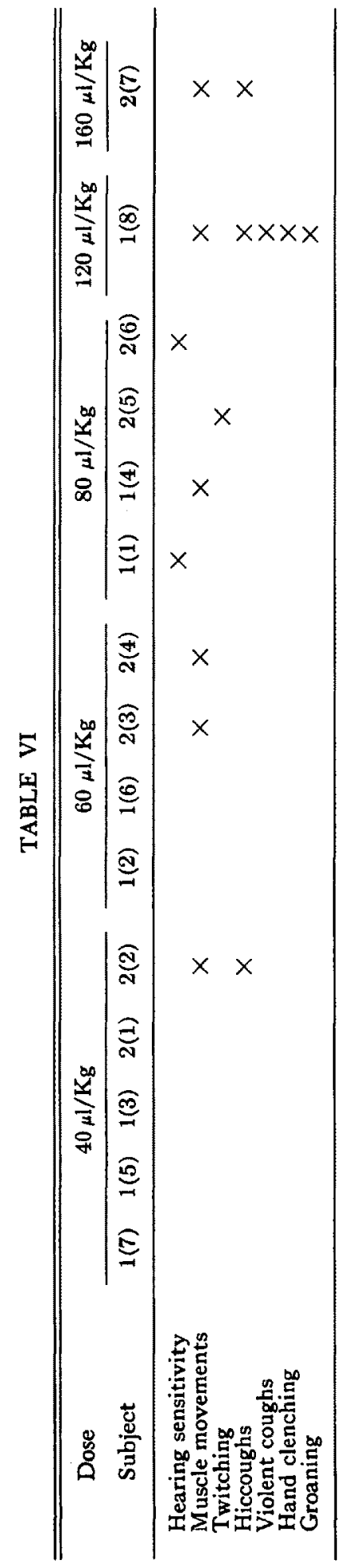


in sleep, as the dose of the drug increases. This might indicate greater sensitivity of the cerebral cortex to increasing doses as compared to the more primitive centres in the brain. (See addendum.)

\section{SUMMARY}

Althesin in dose ranges of 40,60 and $80 \mu \mathrm{l} / \mathrm{Kg}$ was administered to six healthy unpremedicated volunteers according to a balanced incomplete block design. Both subjective and objective changes resulting from the administration of the agent were studied and analyzed.

In the dose ranges used, Althesin was found to have no deleterious effects on heart rate, respiratory rate or blood pressure and apnoea only occurred in one patient who had an end-expiratory $\mathrm{CO}_{2}$ level lower than normal, due to preanaesthetic hyperventilation. The onset of sleep is prolonged with Althesin at the injection rate of $1 \mathrm{ml} / 10$ secs. The onset of anaesthesia is not influenced by the total dose, but the sleep time is directly proportional to the dose injected. Auditory evoked responses tended to lie on a curve which might indicate that with increasing dose the time to reappearance of these responses is not correspondingly prolonged. However, this last observation must be confirmed by studies on a larger scale.

\section{RÉSUMÉ}

Six sujets volontaires en bonne santé, non prémédiqués, ont reçu de l'althesin à des doses de 40,60 et $80 \mu \mathrm{l} / \mathrm{kg}$, selon un plan d'analyse de bloc "randomisé".

Les effets tant subjectifs qu'objectifs de cette médication ont été étudiés et analysés. Pour des doses d'althesin de cet ordre, on n'a pas constaté d'effet nocif sur les fréquences cardiaque et respiratoire et sur la pression artérielle. Un sujet seulement a présenté une période d'apnée mais celui-ci avait déjà au départ une hypocapnie vraisemblablement due à de l'hyperventilation pré-anesthésique.

L'endormissement est prolongé au taux d'injection de $1 \mathrm{ml} / 10 \mathrm{sec}$ utilisé dans cette étude, il est cependant indépendant de la dose totale. La durée du sommeil pour sa part est en fonction directe de la dose injectée.

Les réactions aux stimuli auditifs, c'est à dire le moment où on peut constater une activité vasculaire en réponse à une sollicitation verbale, ont tendance à s'inscrire sur une courbe dont la forme indiquerait que l'augmentation de la dose ne s'accompagne pas nécessairement d'un retard proportionnel du moment d'apparition de ces réactions.

Cependant, d'autres études sur une plus grande échelle devront confirmer cette observation.

\section{AdDendum}

The results obtained with auditory evoked responses have been tested on another five volunteers since completion of the manuscript. Each of them received Althesin in all three dose ranges at random sequence and at intervals of not less than four days. These tests have failed to corroborate our previous observations in that we have now demonstrated a straight-line relationship between the dose administered and the appearance of the evoked responses. 
The other observations with regard to onset and duration of sleep have been confirmed.

\section{REFERENCES}

1. SELye, H. Anaesthetic effects of steroid hormones. Proc. Soc. Exper. Biol. Med. 46: 116$121(1941)$

2. Robertson, S.D. \& WynN Williams, A. Studies on clinical and pathological effects of hydroxydione. Anaesthesia 16:389-409 (1961).

3. ViCKERS, M.D. The measurement of recovery from anaesthesia. Brit. J. Anaesth. 37: 296$302(1965)$.

4. LEwIs, C.D. Statistical Monitoring Techniques. Med. \& Biol. Engin. 9: 315-323 (1971).

5. Hope, C.E., Lewis, C.D., Perry, J.R., \& Gamble, A. Computed trend analysis in automated patient monitoring systems. Brit. J. Anaesth. 45: 440-449 (1973). 